\title{
Persistent nocturnal cough in childhood: a population based study
}

\author{
Titus K Ninan, Lesley Macdonald, George Russell
}

\begin{abstract}
A cross sectional epidemiological study was carried out to investigate the validity of persistent nocturnal cough (PNC) as an independent marker of childhood asthma. A screening questionnaire on respiratory symptoms was applied to 4003 children attending primary schools in Aberdeen, after which 799 symptomatic children and a random selection of 229 asymptomatic children were invited to attend for a diagnostic interview. Six hundred and seven (359 boys and 248 girls) symptomatic children and 135 asymptomatic children ( 57 boys and 78 girls) were selected from the screening questionnaires. Of 607 children with respiratory symptoms when interviewed, 27 (nine boys and 18 girls) had isolated PNC, and 97 (51 boys and 46 girls) had multiple symptoms (polysymptomatic asthma).
\end{abstract}

The incidence of prematurity was highest in the group with PNC (19\%). The prevalence of hay fever in children with PNC $(11 \%)$ was similar to that of the asymptomatic group (15\%) and less than that in the group with polysymptomatic asthma $(41 \%)$. Eczema was twice as common in the PNC $(19 \%)$ as in the asymptomatic children $(10 \%)$ but only half as common in the polysymptomatic asthma group $(35 \%)$. The prevalence of a parental history of hay fever was similar in all three groups. The prevalence of a parental history of eczema was similar in the PNC (7\%) and asymptomatic (7\%) groups but higher in the polysymptomatic asthma group (22\%). The prevalence of a history of parental asthma was $30 \%$ in children with PNC, $13 \%$ in the asymptomatic group, and $42 \%$ in those with polysymptomatic asthma. The parents of three $(11 \%)$ children with PNC were aware of a diagnosis of asthma; two of these children (7\%) were on inhaled bronchodilator treatment and one $(4 \%)$ was on a slow release theophylline preparation. Using a stepwise discriminant analysis procedure, in $18(67 \%)$ children with PNC predicted membership was in the asymptomatic group and only nine $(33 \%)$ children with PNC were grouped into the polysymptomatic asthma category. It is concluded that the clinical features of children with PNC resembled those of the asymptomatic population more closely than those of the polysymptomatic asthmatic population. In this age group PNC, in the absence of wheeze, shortness of breath or tightness in the chest, is likely to be a manifestation of atypical or hidden asthma in only a minority of cases. (Arch Dis Child 1995; 73: 403-407)

Keywords: asthma, persistent nocturnal cough, parental atopy.

A recent study in Australian children reported a prevalence of nocturnal cough in the absence of wheeze of $14.5 \%$ at the age of 7 years and $9.5 \%$ at the age of 12 years. $^{1}$ It is now well established that in some cases isolated persistent cough may be the sole presenting manifestation of asthma. ${ }^{23}$ The diagnosis of asthma is relatively easily made when cough is associated with wheeze, shortness of breath, and tightness in the chest. ${ }^{45}$ It is much more difficult to sustain a diagnosis of asthma in children who present with cough as the only respiratory symptom. In such cases the differential diagnosis may include postnasal drip, viral and mycoplasma respiratory tract infections, and recurrent gastro-oesophageal reflux as well as asthma. It has been argued that bronchial provocation tests and/or a vigorous trial of bronchodilator and/or corticosteroid treatment may help in reaching a diagnosis. ${ }^{67}$ The aims of this study, which was part of a larger community based study of respiratory symptoms in childhood, ${ }^{8}$ were to identify the characteristics of children with isolated persistent nocturnal cough (PNC), and to compare them with those of children with multiple symptoms suggestive of asthma, including cough, and with those of asymptomatic children drawn from the same total population.

Subjects and methods

Permission for the study was obtained from the Director of Education and the joint ethical committee of the University of Aberdeen and Grampian Health Board. Data on respiratory symptoms were gathered by means of a screening questionnaire circulated to the parents of 4003 schoolchildren between the ages of 8 and 13 years attending primary schools in Aberdeen. This was followed up by a diagnostic interview. Up to three postal reminders were sent and one telephone call was made to improve the attendance rate at the diagnostic interview. The details obtained at the interview form the database for this analysis. Of the 851 children identified as symptomatic on the screening questionnaire, 799 were invited to attend for interview. This group included a random sample of the children who reported ever having had isolated PNC in the screening questionnaire, and all other children with 
respiratory symptoms. Fifty two children were not invited because they had no reported symptoms for over three years or they had had one isolated incident of respiratory symptom after an infective episode. Of the 2539 children identified as asymptomatic in the screening questionnaire, 229 (a random one in 11 sample) were invited to attend for interview. Six hundred $(75 \%)$ of the 799 symptomatic children and $141(62 \%)$ of the 229 asymptomatic children attended for a detailed respiratory questionnaire. The parents and the children were interviewed and data regarding respiratory symptoms, perinatal events, atopic history, parental smoking habits, history of damp housing, diagnosis, and treatment were gathered.

\section{DEFINITION OF STUDY GROUPS}

Based on symptoms current at the time of the interview, three separate groups of children were identified and defined. (1) PNC: a group of 27 children with a history of isolated PNC of at least four weeks' duration, having had at least three such episodes (or continuous symptoms) in the past 12 months. (2) Polysymptomatic asthma: a group of 97 children with polysymptomatic asthma, each with a history of episodes of wheeze, shortness of breath, tightness of chest, and PNC, each at least three times in the past 12 months. (3) Asymptomatic: a group of 135 children with no history of respiratory symptoms in the last three years and currently receiving no antiasthma medication.

\section{STATISTICAL ANALYSIS}

Data were analysed using the SPSS package on the CMS system at the University of Manchester Computer Centre. Data on the groups were presented as contingency tables and analysed using $\chi^{2}$ tests. A stepwise discriminant analysis using damp housing, sex, birth weight, gestational ages, admission to special care nursery, present or past history of eczema, hay fever, parental history of asthma, eczema, or hay fever, and parental smoking was used to predict the group into which the children would best fit.

\section{Results}

SEX DIFFERENCES

There were no significant sex differences between the three groups of children (fig 1).

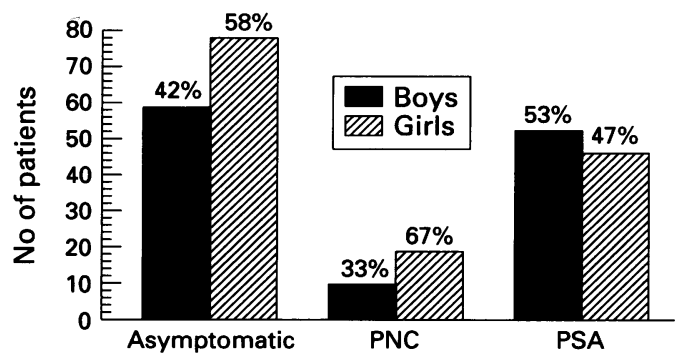

Figure 1 Sex differences between the three groups (PNC = persistent nocturnal cough, PSA=polysymptomatic asthma); overall $\chi^{2}=4 \cdot 15,2 d f, p=0 \cdot 126$.

\section{BIRTH EVENTS}

The children with PNC included a significant excess of babies who were premature (19\%). They also had the highest proportion with low birth weight, although it did not differ significantly from that in the group with polysymptomatic asthma. This comparison may be affected by the number of girls in the PNC group (fig 2).

\section{PERSONAL HISTORY OF ATOPY}

At $19 \%$ the prevalence of eczema in the children with PNC was intermediate between that of the asymptomatic (10\%) and polysymptomatic asthma $(35 \%)$. In contrast the prevalence of hay fever in the children with PNC $(11 \%)$ resembled that of the asymptomatic children $(15 \%)$ but was appreciably less than that of the children with polysymptomatic asthma (41\%) (fig 3 ).

\section{PARENTAL HISTORY OF ATOPY}

The prevalence of parental history of asthma in the children with PNC (30\%) lay between that of the asymptomatic children (13\%) and the children with polysymptomatic asthma (42\%). History of parental eczema in the children with PNC was similar to that of the asymptomatic children $(7 \%)$ but was much higher in the children with polysymptomatic asthma (22\%). There were no significant differences between the groups in the prevalence of parental history of hay fever (fig 4).

\section{ENVIRONMENTAL FACTORS}

Children with polysymptomatic asthma were more likely to have a smoker in the household
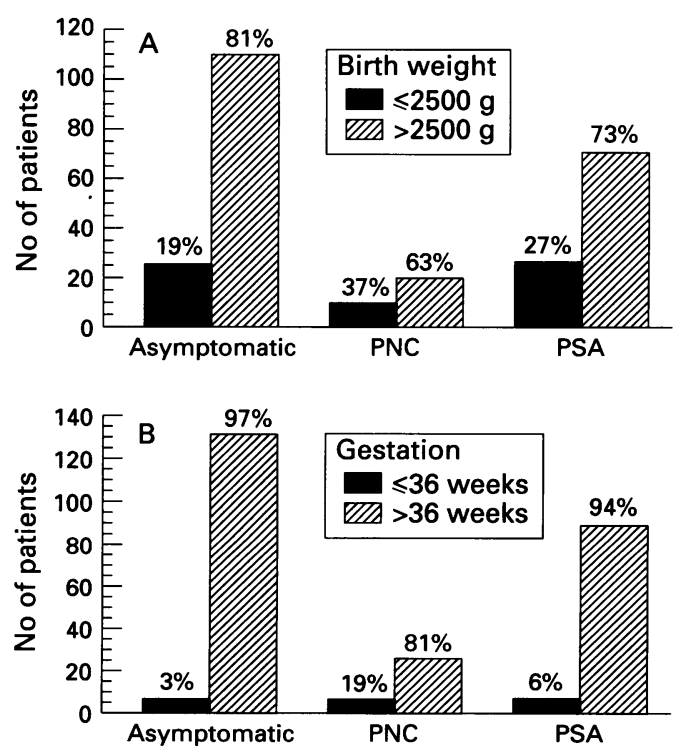

Figure 2 Birth events in the three groups

(PNC=persistent nocturnal cough, PSA = polysymptomatic asthma). (A) Birth weight: overall $\chi^{2}=5 \cdot 07,2 d f$, $p=<0 \cdot 1 ; P N C$ v $P S A \chi^{2}=1 \cdot 07,1 d f, p=0 \cdot 300 ; P S A$ v asymptomatic $\chi^{2}=2 \cdot 17,1 \mathrm{df}, p=0 \cdot 141 ; P N C \mathrm{v}$ asymptomatic $\chi^{2}=4 \cdot 46,1 d f, p<0.05,(B)$ Gestation: overall $\chi^{2}=10 \cdot 02,2 d f, p<0.01 ; P N C$ v PSA (Fisher's exact test) $p<0 \cdot 1 ; P S A$ v asymptomatic (Fisher's exact test) $p=0.327 ; P N C \mathrm{v}$ asymptomatic (Fisher's exact test) $p<0 \cdot 1$. 

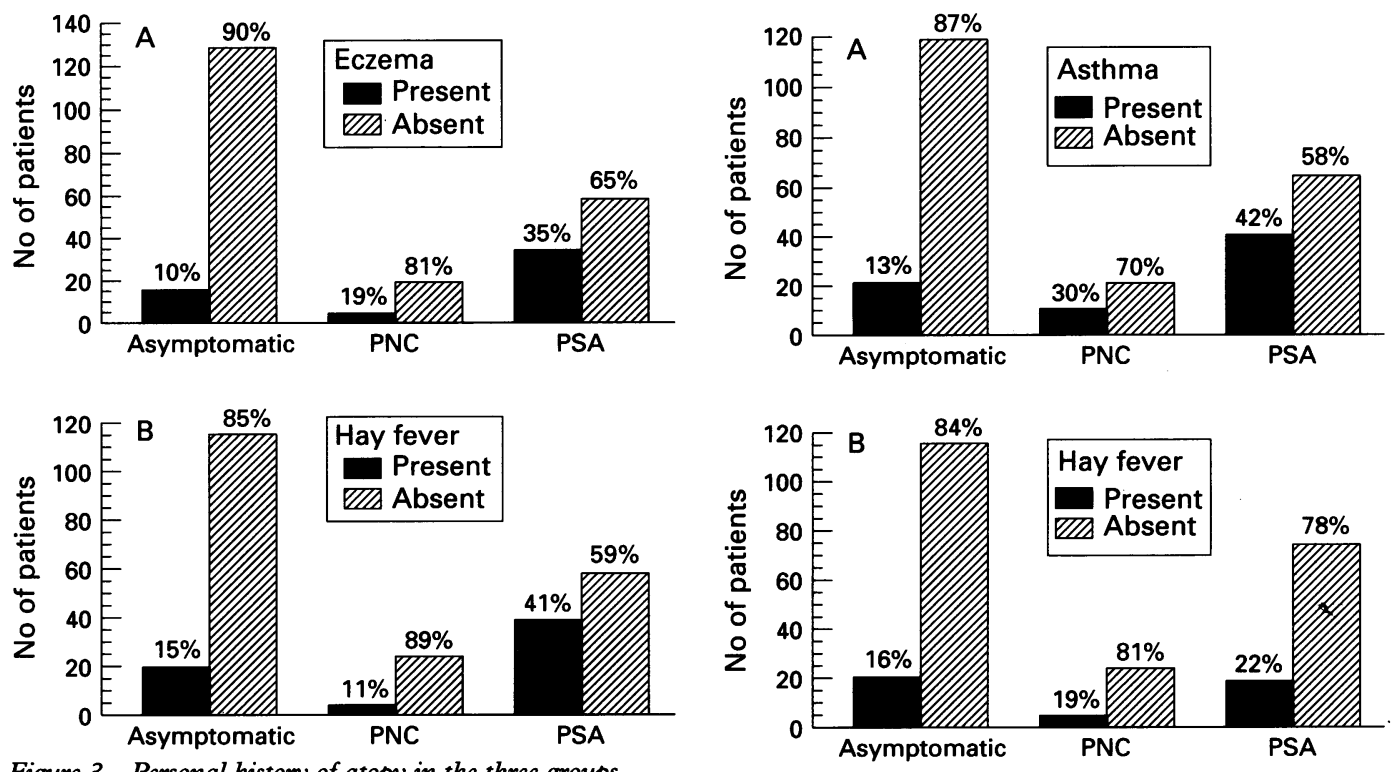

Figure 3 Personal history of atopy in the three groups (PNC=persistent nocturnal cough, $P S A=$ polysymptomatic asthma). (A) Eczema: overall $\chi^{2}=22 \cdot 77,2 d f, p<0 \cdot 001$; $P N C$ v $P S A \chi^{2}=2 \cdot 68,1 d f, p=0 \cdot 101 ; P S A$ v asymptomatic, $\chi^{2}=22 \cdot 58,1 \mathrm{df}, p<0.001 ; P N C \mathrm{v}$ asymptomatic (Fisher's exact test) $p=0 \cdot 187$. (B) Hay fever: overall $\chi^{2}=24 \cdot 26,2 d f, p<0 \cdot 001 ; P N C$ v $P S A$ $\chi^{2}=8.46,1 d f, p<0.005 ; P S A$ v asymptomatic $\chi^{2}=20.55 ; 1 d f, p<0.001 ; P N C \mathrm{v}$ asymptomatic (Fisher's exact test) $p<0 \cdot 769$.

than either of the other two groups, although the presence of two or more smokers had no extra effect. There were no significant differences between the smoking habits in the adults of the PNC and asymptomatic groups (fig 5). The prevalence of a history of damp housing was least $(2 \%)$ in the controls and maximum $(13 \%)$ in the children with polysymptomatic asthma (fig 5).

DIAGNOSIS AND TREATMENT REGIMENS

Asthma had been diagnosed in three of the children with PNC, in none of the symptomatic children and in 60 of the polysymptomatic asthma group. Bronchodilators had been prescribed for two of the PNC group, one of the asymptomatic children, and 62 of the children with polysymptomatic asthma (fig 6).

DISCRIMINANT ANALYSIS BETWEEN POLYSYMPTOMATIC ASTHMA AND ASYMPTOMATIC GROUPS

Of the 11 variables considered only personal history of eczema, hay fever, and damp housing contributed significantly to the final discrimination between the asymptomatic and the group with polysymptomatic asthma, although parental history of asthma nearly reached significance (table). This correctly classified 104 $(78 \%)$ of the asymptomatic children and 67 $(69 \%)$ of the children with polysymptomatic asthma. Of the 27 children with PNC 18 $(67 \%)$ were classified as asymptomatic and nine $(33 \%)$ as having polysymptomatic asthma: much closer to the classification proportions of the asymptomatic children than to those of the children with polysymptomatic

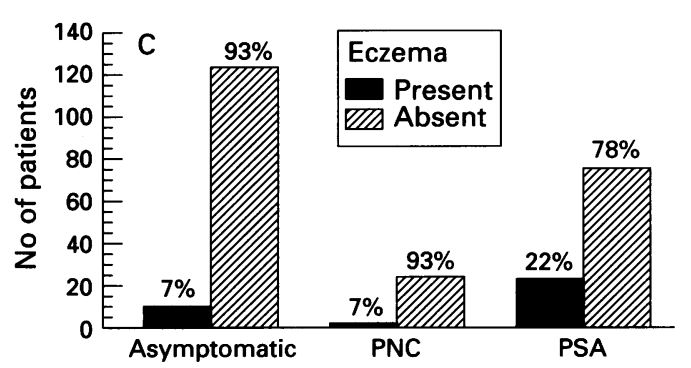

Figure 4 Parental history of atopy in the three groups (PNC=persistent nocturnal cough, PSA = polysymptomatic asthma). (A) Asthma: overall $\chi^{2}=26.45,2$ df, $p<0.001$; $P N C$ v $P S A \chi^{2}=1.41,1 d f, p=0.234 ; P S A$ v asymptomatic $\chi^{2}=26.51,1 \mathrm{df}, p<0 \cdot 001, P N C \mathrm{v}$ asymptomatic (Fisher's exact test) $p<0.05$. (B) Hay asymptomatic (Fisher's exact test) $p<0.05$. (B) Hay
fever: overall $\chi^{2}=1.41,2 d f, p=0.493, P N C$ v $P S A$ fever: overall $\chi^{2}=1 \cdot 41,2 d f, p=0 \cdot 493, P N C$ v $P S A$
$\chi^{2}=0 \cdot 12,1 d f, p=0 \cdot 721 ; P S A$ v asymptomatic $\chi^{2}=1 \cdot 14$, $1 \mathrm{df}, p=0 \cdot 234 ;$ PNC $\mathrm{v}$ asymptomatic (Fisher's exact test) $p=0.44$. (C) Eczema: overall $\chi^{2}=11.01,2 d f, p<0.005$; $P N C \vee P S A \chi^{2}=2 \cdot 84,1 d f, p<0 \cdot 1 ; P S A$ v asymptomatic $\chi^{2}=9 \cdot 89,1 d f, p=0.005 ; P N C \mathrm{v}$ asymptomatic (Fisher's exact test) $p=1 \cdot 00$.

asthma. Not all the assumptions necessary for a linear discriminant analysis are satisfied here (in particular all variables in the final equation and most of the others considered are binary) so the numbers and significance levels in the table should be regarded as approximate.

\section{Discussion}

Cough variant asthma is now a well established entity in childhood. ${ }^{2} 3$ Konig identified asthma among children attending a hospital clinic with isolated persistent cough by treating them with bronchodilators and monitoring their response to treatment. ${ }^{9}$ Hannaway and Hopper, in a population of children with nocturnal cough subject to long term hospital follow up, found

Linear discriminant analysis

\begin{tabular}{llll}
\hline $\begin{array}{l}\text { Order of } \\
\text { entering } \\
\text { equation }\end{array}$ & $\begin{array}{l}\text { Significance } \\
\text { at entry }\end{array}$ & $\begin{array}{l}\text { Standardised } \\
\text { discriminant } \\
\text { coefficient }\end{array}$ & Wilks $\lambda$ \\
\hline Eczema & $<0.0001$ & 0.637 & 0.904 \\
Hay fever & $<0.0001$ & 0.598 & 0.840 \\
Damp & $<0.0005$ & 0.488 & 0.800
\end{tabular}

Discriminant function $=-9 \cdot 217+1 \cdot 419$ (hay fever) $+1 \cdot 655$ (eczema) +1.957 (damp). 

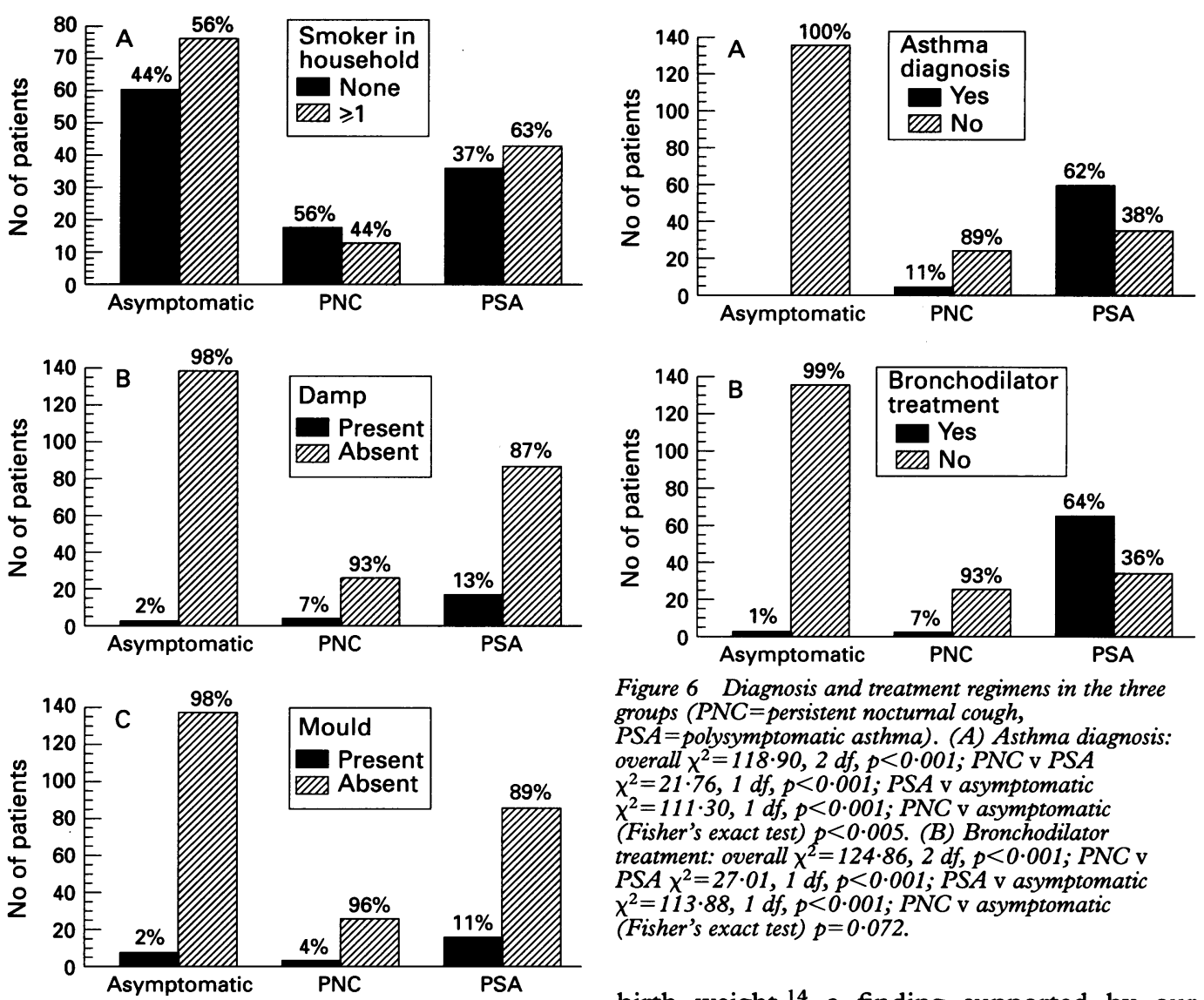

Figure 5 Environmental factors in the three groups (PNC= persistent nocturnal cough, $P S A=$ polysymptomatic asthma). (A) Smoker in household: overall $\chi^{2}=10 \cdot 72$, $2 d f, p<0.1 ; P N C$ v $P S A \chi^{2}=7.614,1 d f, p<0.05 ; P S A$ $\mathrm{v}$ asymptomatic $\chi^{2}=5 \cdot 82,1 \mathrm{df}, p<0 \cdot 05 ; P N C \mathrm{v}$ asymptomatic $\chi^{2}=2 \cdot 33,1 \mathrm{df}, p=0 \cdot 311$. (B) Damp: overall $\chi^{2}=10 \cdot 81,2 d f, p<0 \cdot 005 ; P N C$ v PSA (Fisher's exact test) $p=0 \cdot 520 ; P S A \mathrm{v}$ asymptomatic $\chi^{2} 10 \cdot 99,1 d f$ $p<0.001 ;$ PNC $\mathrm{v}$ asymptomatic (Fisher's exact test) $p=0 \cdot 194$. (C) Mould: overall $\chi^{2}=8 \cdot 84,2 d f, p=0 \cdot 012$; $P N C$ v PSA (Fisher's exact test) $p=0.460 ; P S A \mathrm{v}$ asymptomatic $\chi^{2}=8.28,1 d f, p<0.001 ; P N C \mathrm{v}$ asymptomatic (Fisher's exact test) $p=0 \cdot 521$.

that three quarters of them developed mild to moderate asthma with typical symptoms of wheeze and shortness of breath. ${ }^{2}$ Parks et al suggested that in children with persistent cough treatment should not be considered complete unless a short course of high dose oral steroids has been included. ${ }^{7}$ Bronchial provocation tests may be an additional tool to help reach a diagnosis. ${ }^{7-13}$ There are, however, few community based studies of isolated PNC in childhood though the prevalence of the symptom may vary between $9.5 \%$ and $17 \cdot 3 \% .{ }^{1}$ The validity in community based studies of isolated PNC as an independent marker of childhood asthma is unknown and this paper attempts to address this question.

It has been argued previously that a diagnosis of asthma can be established in children with persistent cough if in addition they have a personal or family history of atopy and a raised eosinophil count. ${ }^{3}$ In our study we found that in children with PNC the prevalence of a personal and family history of atopy resembled that in the asymptomatic rather than the polysymptomatic asthma group. Chan et al found that the prevalence of cough was significantly increased in children who had been of low

Figure 6 Diagnosis and treatment regimens in the three groups (PNC=persistent nocturnal cough,

PSA = polysymptomatic asthma). (A) Asthma diagnosis: overall $\chi^{2}=118.90,2 d f, p<0.001 ; P N C$ v $P S A$ $\chi^{2}=21 \cdot 76,1 d f, p<0 \cdot 001 ; P S A \mathrm{v}$ asymptomatic $\chi^{2}=111 \cdot 30,1 \mathrm{df}, p<0.001 ; P N C \mathrm{v}$ asymptomatic (Fisher's exact test) $p<0.005$. (B) Bronchodilator treatment: overall $\chi^{2}=124 \cdot 86,2 d f, p<0 \cdot 001 ; P N C v$ $P S A \chi^{2}=27 \cdot 01,1 d f, p<0 \cdot 001 ; P S A$ v asymptomatic $\chi^{2}=113 \cdot 88,1 d f, p<0.001 ; P N C \mathrm{v}$ asymptomatic (Fisher's exact test) $p=0.072$.

birth weight, ${ }^{14}$ a finding supported by our study (fig 2).

Hannaway and Hopper, ${ }^{2}$ Yahav et $a l^{3}$ and Konig ${ }^{9}$ diagnosed asthma in each of their cohorts by the response to a therapeutic trial of bronchodilator treatment. In a community based survey, we were not in a position to offer treatment to the subjects, and information on response to bronchodilator treatment is therefore not available. Not surprisingly, bronchodilators had been prescribed for over $60 \%$ of the children with polysymptomatic asthma but for only $12 \%$ of the 27 children with PNC.

We found that isolated PNC is not uncommon in the childhood population. Although our analysis is based on data relating to only those 27 children from the random selection of children with PNC asked to attend hospital, and who were currently suffering from this symptom at the time of the diagnostic interview, the overall prevalence of this symptom in our screening questionnaire was $4.9 \%$ and, given the known unreliability of parental observation in PNC, ${ }^{15} 16$ it is likely that we failed to uncover many cases. In the absence of cough, tightness in the chest and shortness of breath, in only a small proportion of children with PNC did the presence of other characteristics suggest that they could be grouped with the children who had polysymptomatic asthma. The findings of this study are similar to the findings of Clifford et al who have questioned the relevance of PNC as a marker of asthma in the absence of wheeze. ${ }^{17}$ It is therefore concluded that in children aged 8 to 13 years PNC on its own is infrequently a clinical marker for asthma very much in keeping with a recently published annotation. ${ }^{18}$ 
We thank Allen and Hanburys, the National Asthma Campaign and Astra Pharmaceuticals for financial assistance, John Lemon for helpful statistical advice, and the Director of Education and the head teachers for their active cooperation.

1 Robertson CF, Heycock E, Bishop J, Nolan T, Olinsky A, Phelan PD. Prevalence of asthma in Melbourne school children: changes over 26 years. $B M \mathcal{F} 1991$; 302: 1116-8.

2 Hannaway PJ, Hopper GDK. Cough variant asthma in children. $\mathscr{F A M A}$ 1982; 247: 206-8.

3 Yahav Y, Katznelson D, Benzaray S. Persistent cough - a forme fruste of asthma. Eur $\mathcal{F}$ Respir Dis 1982; 63: 43-6.

4 Mellis CM. Evaluation and treatment of chronic cough in children. Pediatr Clin North Am 1979; 26: 553-64.

Williams HE. Chronic and recurrent cough. Aust Paediatr $\mathcal{f}$ 1975; 11: 1-18.

6 de Benedictis FM, Canny GI, Levison $H$. Methacholine inhalation challenge in the evaluation of chronic cough in

7 Parks DP, Ahrens RC, Humphries CT, Weinberger MM Chronic cough in childhood: approach to diagnosis and Chronic cough in childhood: approach

8 Ninan TK, Russell G. Respiratory symptoms and atopy in
Aberdeen schoolchildren: evidence from two surveys 25 years apart. $B M \mathcal{F}$ 1992; 304: 873-5.

9 Konig P. Hidden asthma in childhood. Am $\mathcal{F}$ Dis Child 1981; 135: 1053-5.

10 Corrao WM. Methacholine challenge in the evaluation of chronic cough. Allergy Proc 1989; 10: 313-5.

11 Parrillo SJ. Cough variant asthma. Pediatr Emerg Care 1986; 2: 97-101.

12 Parrillo SJ. Cough variant asthma. Pediatr Emerg Care 1987; 3: 9 .

13 Cloutier MM, Loughlin GM. Chronic cough in children: a manifestation of airway hyperreactivity. Pediatrics 1981; 67: 6-12.

14 Chan KN, Elliman A, Bryan E, Silverman M. Respiratory symptoms in children of low birth weight. Arch Dis Child 1989; 64: 1294-304.

15 Archer LNJ, Simpson H. Night cough counts and diary card scores in asthma. Arch Dis Child 1985; 60: 473-4.

16 Falconer A, Oldman C, Helms P. Poor agreement between reported and recorded nocturnal cough in asthma. Pediat Pulmonol 1993; 15: 209-11.

17 Clifford RD, Howell JB, Radford M, Holgate ST Association between respiratory symptoms, bronchial response to methacholine and atopy in two age groups of schoolchildren. Arch Dis Child 1989; 64: 1133-9.

18 McKenzie S. Cough - but is it asthma? Arch Dis Child 1994; 70: 1-2. 